be exercised in its preparation by the pharmacist and in its administration by the physician. It is $\mathrm{my}$ practice to have the drug rubbed up dry with the pul. verized resin of guaiac placed in capsules, and given one hour before meals; or, in more urgent cases, I have it prepared freshly in solution and use it hypodermatically, thus hoping to avoid by the one method or the other the destruction of the drug in the stomach. This drug being a tonic, as well as an alterative, it is indicated in the several stages of the disease and may be continued with advantage for months at a time.

The next drug upon which I place reliance is a preparation of phosphorus, and for this purpose prefer the phosphid of zinc. This I give in the eighth (.008 gram) or tenth (.006 gram) of a grain doses, three times a day after meals. As a tonic and alterative, in alternation with the above I use arsenic, preferring the arsenate of sodium in about the twelfth of a grain (.0054 gram) doses, to any other of the preparations of arsenic.

When the disease has taken upon itself a rapid developmental state, full doses of ergot with the rest before indicated will sometimes stop the rapid progression of the disease. For the pains I have found that extract of cannabis indica, injections of cocain, and acetanilid alone, or in combination, are the most successful. I have seen no especially beneficial results from the use of nitrate of silver, aluminum chlorid or of mercury in ordinary cases, and my experience is emphatically against the use of strychnia in this disease. I am very confident that I have seen more than one case very greatly injured by the use of even ordinary doses of strychnia.

\section{GUMMATA OF THE HEART IN A CASE OF CONGENITAL SYPHILIS.}

FROM THE PATHOLOGICAL LABORATORX OF RUSH MEDICAL COLLEGE.

Read before the Chicago Patbological Society, Jan. 11. 1897. BY E. R. LeCOUNT, M.D. DEMONSTRATOR OF PATHOLOGY. CHICAGO, ILI.

The following case is of interest as an instance of a lesion observed very infrequently, viz: gummata of the heart as a feature of congenital syphilis.

A child born at term, of young parents, died almost immediately following birth and was sent to the laboratory of Rush Medical College by Dr. A. B. Strong, of Ohicago, in whose practice the case occurred and to whom I am indebted for the opportunity of making the examination.

Autopsy Abstract.-Weight 2,500 gm., length 50 cm.; the umbilical cord showed a recent ligature. The external surface of the body was the seat of a vesicular and pustular inflammation, most marked over the face, hands, feet and buttocks. The contents of these eruptions, although generally clear, were occasionally seropurulent and less often of soft, cheese-like necro. tic material. The peritoneum was normal and its cavity empty. The thymus weighed $7.5 \mathrm{gm}$., and possessed several softened areas containing gray viscid pus. ${ }^{1}$ The thyroid, submaxillary and parotid glands were normal in appearance except for an excess of blood. The pleural cavities were empty. The lungs contained numerous firm, white nodules, some of them

1 The mized infection which had resulted in this case was investigated ical Society (Transactions ChIcago Path. Soc., Vol. 1I, 1897). as large as cherries. On section these presented a smooth surface and appeared of equal consistency throughout. The lung tissue was non-crepitant or very slightly crepitant, fairly firm and oozed dark blood. The pleura over the left lower lobe was roughened by an easily removable fibrinous exudate. The liver was engorged with blood and extended to the level of the umbilicus. The spleen was slightly enlarged and congested; the pancreas was negative; the kidneys, stomach, intestines, lymphatic apparatus and the central nervous system all appeared unchanged.

The lines of ossification in both long and flat bones were irregular, wider than normal, and hemorrhagio.

The heart.--On the anterior surface of the heart midway between the base and the apex, involving that part of the ventricular wall which faces toward the left, and also overlapping the ventricular septum, was a white area, quite circular in form and measuring approximately $1 \mathrm{~cm}$. in diameter. The edge of this white area fused gradually with the adjacent heart tissue, and on section appeared less firm than the unchanged myocardium (Fig. 1.) It was seen to involve the entire thickness of the ventricular wall, spreading out more as it approached the pericardium, which was unchanged except as to color. The change in the muscle also extended into the columnæ carneæ of the left ventricle. On the posterior or diaphragmatic surface, near the right border of the heart, were situated three smaller but similar areas.

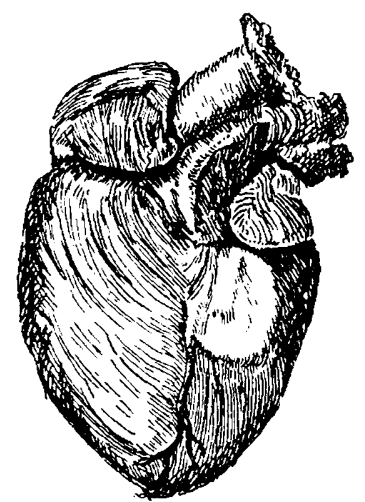

FIg. 1.-Gumma near the interventricular septum.

The heart cavities contained considerable blood partially coagulated. The valves and orifices showed no changes.

Anatomic diagnosis.--Congenital syphilis, syphilitic interstitial pneumonia (nodular); syphilitic osteochondritis; gummata of the heart; pustular syphilides of the skin; multiple abscesses of the thymus; hyperemia of the liver and spleen.

Microscopic examination.-The presence of syphilis was confirmed by the examination of the viscera, characteristic changes being found in the liver, lungs, spleen and lines of epiphyseal ossification. In sections made through the large lesion on the anterior surface of the heart, the following changes were found: Between the heart muscle fibers throughout the area, which to the naked eye appeared white, there existed a marked infiltration of round or partially fibrillated cells, with faintly staining vesicular nuclei. Although the change prevailed throughout it was most marked around the blood vessels (small arterioles). The change here began immediately outside the media, where distorted cells and cells of peculiar shapes, with faintly stained nuclei occurred. These were evidently formative cells, and resulted from proliferative 
changes in the adventitia (Fig. 2). Occasionally mitotic nuclear figures were here met with.

A marked proliferation of the subpericardial connective tissue bad also taken place and the resulting new cells had invaded the heart muscle to a considerable depth. The phenomena observed resulting from leucocytic invasion were: 1. Leucocytes of the polymorphous variety in transit through the vessel wall (Fig. 2). This was distinct and frequent, resulting

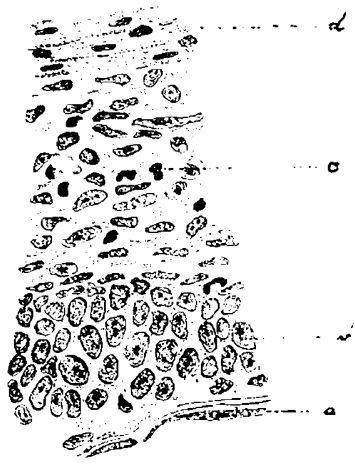

Frg. 2.-Showing the proliferation of the adventitia. a, intima of a small arteriole; $b$, nuclei of the muscle cells in the tunica media; $c$, in, 2, accumulations of leucocytes in the adventitia among the formative cells. 3. The occasional presence of single leucocytes at long distances from the vessels where all changes were slight and, 4 , the accumulation of leucocytes in foci in which degeneration and necrosis of heart muscle fibers had taken place (Fig. 3). Not only had muscle fibers disappeared in such areas, but in some foci nuclear fragmentation of all the cells in the center of the focus had resulted and dust-like chromatin elements of the degenerated cells occupied that region. No bacteria were found in these foci of necrosis. Multinuclear cells were present in the perivascular cell increase, but the nuclei of such were closely set together and showed no peripheral arrangement or central necrosis as is so frequent in the giant-cells of acquired syphilis. No changes were found in or about the veins or in the endocardium.

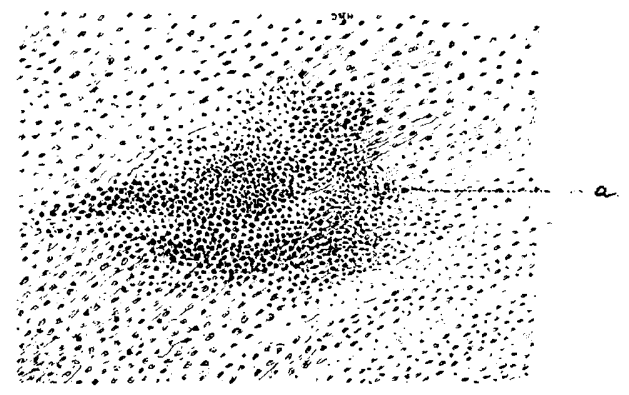

FIc. 3.-Area of necrosis and round cell intiltration. a, leucocytes.

The literature on congenital syphilis of the heart has been thoroughly summarized by Ludvig Hektoen in a case recently reported of "Multiple Foci of Interstitial Myocarditis in Hereditary Syphilis" (Journal of Pathology and Bacteriology, Edinburgh and London, January, 1896), and a search througb the Index Medicus revealed no additional cases reported since his summary. The author above mentioned was able to find only nine previously recorded cases of hereditary syphilis of the heart, and these were collated in the well-known treatise by Mracek. ${ }^{2}$ In 112 cases of heart syphilis considered by Mracek, nine had to do

\footnotetext{
2 "Die Syphilis des Herzens bei erworbener und ererbter Lues.". Arch.
}

f. Dermat. u. Syph., Wien, Ergänzungsheft, i1, 1893 . with hereditary syphilis and the syphilitic nature of some of these was doubtful.

Conclusions.-That this is an instance of syphilitic myocarditis is conclusively proven by the changes present in other viscera and the syphilitic osteochondritis. The title of "gummata" is simply a matter of preference; multiple foci of interstitial myocarditis with leucocytic invasion, areas of degeneration of the heart muscle and the occurrence of multinuclear cells resulted in areas which to the naked eye were of lim. ited extent, whitish, and appeared softened, in other words, gummatous.

\section{WHAT WE EAT AND WHAT IT COSTS. BY D. H. GALLOWAY, M.D. CHICAGO.}

Few of us have any idea of the number of kinds of food which we eat in a year or of their absolute or relative cost. Man is said to be an omnivorous animal and this is generally taken to mean that he eats about equally of animal and vegetable food. The feeding of people collectively, as in the large public institutions, is not a test of the amount and variety of food consumed by the average man nor of the cost of it. Some time ago one of the Chicago papers instituted a prize competition for the best bill of fare which could be furnished for $\$ 500$ a yeur for a family of five persons. This brought forward a great many statements of the cost of living. Some of these were doubtless accurate, while many others bore such evidence of inaccuracies as to make them worthless.

There is no question but that some persons habitually eat vastly more than others; one family may eat more expensive food than another without necessarily being better fed; in fact the value of food may be in inverse ratio to its cost. While in college I had a roommate who weighed 250 pounds, which was just about twice my weight. We occupied the same room, were about the same age, attended the some classes and in many ways our habits were similar. We took our meals at a co-operative boarding club of thirty students. Without our knowledge, some of our fellowboarders kept a record of the approximate quantity of food which we ate in a week and they found that my heavy roommate ate more than three times as much as I did. Obese people are not always extraordinarily large eaters, but they usually are and they eat excessively of heat- and fat-producing foods. Some persons eat too little and keep their vital fires too low, but there are many more who eat too much.

Eating too much food, or food that is unsuitable, or at an unsuitable time or in an unsuitable manner, is the principal cause of the great number of distressing affections which go by the various names of dyspepsia, indigestion, etc., and every physician will testify to the great prevalence of these diseases in this country. Probably more suffering is caused by errors of eating than by the use of alcoholic beverages, enormous as the latter undoubtedly is. Not all they pay for is eaten by every family. The margin of waste in some is a very large factor, while in others practically nothing is wasted. In households where the culinary department is left to servants who are not constantly watched, a larger or a smaller percentage of the food cooked finds its way into the garbage can. Quantities of meat and vegetables, too small to make another meal, are thrown out and stale bread is disposed of in the same manner. In other families these things 